\title{
Exploring ADS-B as an Alternative Data Source for Flight Data Monitoring of General Aviation
}

\author{
Chenyu Huang \\ Purdue University \\ Mary E. Johnson \\ Purdue University
}

\begin{abstract}
Flight data monitoring (FDM) is believed to be effective for mitigating risks of aviation accidents by the International Civil Aviation Organization (ICAO) and major airlines who implemented flight data monitoring programs. In the United States, flight data monitoring is recommended by the Federal Aviation Administration (FAA) as a voluntary safety program, namely the flight operational quality assurance (FOQA) program. However, implementing a FDM program not only requires an expensive investment on technological equipment, but also involves long-term labor costs to regularly collect and analyze flight data after flights are completed. Especially for general aviation (GA), implementation of a FDM program using on-board flight data recorder equipment may be too expensive for some owners or operators. Automatic Dependent Surveillance Broadcast Out (ADS-B Out) is a precise satellite-based surveillance system which can continually broadcast flight data. The broadcasted flight data can be received by other nearby ADS-B In capable aircraft or ground-based ADS-B receivers. This paper explores the ADS-B as an alternative data source of FDM for GA. First, the structure and content of flight data broadcast by ADS-B Out are analyzed. Then, based on the basic flight parameters, additional flight parameters are derived, and flight metrics are developed from the standpoint of flight operation analysts. Finally, the potential of ADS-B for supporting FDM is discussed.
\end{abstract}

\section{Introduction}

Comprising both commercial and general aviation, civil aviation is playing an important role in supporting global economic activities and development as a worldwide rapid transportation system. In 2015, commercial aviation transported approximately 3.6 million passengers, carried 51.2 million tons of freight and 35 percent of interregional exports of goods by value (International Air Transport Association, 2016).

Aviation safety is one of the major factors necessary for air transportation to generate stable and positive economic and social benefits. To improve aviation safety is one of the most fundamental objectives of the International Civil Aviation Organization (ICAO) and of the Federal Aviation Administration (FAA). Corresponding safety enhancement measures have been widely undertaken globally to address aviation risks (International Civil Aviation Organization, 2016). With continuous efforts and cooperation by aviation stakeholders, the total number of aviation accidents and the accident rates have decreased over the last years. According to the ICAO Safety Report 2016, the number of accidents worldwide, as defined in ICAO Annex 13, decreased by 5 percent to 92 in 2015 
compared to 2014, and the global accident rates involving scheduled commercial operations decreased by 7 percent to 2.8 accidents per million departures in 2015 compared to 2014 (International Civil Aviation Organization, 2016). In Destination 2025, the FAA made reducing the general aviation accident rate one of its top priorities and set a goal of "no more than 1 fatal accident per 100,000 hours of flight by 2018" (FAA, n.d., p. 4). In the United States, general aviation (GA) had 1223 accidents, 257 fatal accidents and 444 fatalities in calendar year 2014 (NTSB, 2016). The GA fatal accident rate has fallen from 1.17 fatal accidents per 100,000 GA flight hours in fiscal year 2009 to 1.03 fatal accidents per 100,000 GA flight hours in fiscal year 2015 (GAJSC, 2016).

Flight data monitoring (FDM) is believed to be effective for mitigating risks of aviation accidents by the International Civil Aviation Organization (ICAO) and major airlines who implemented flight data monitoring programs. In the United States, flight data monitoring is recommended by the Federal Aviation Administration (FAA) as a voluntary safety program, namely the flight operational quality assurance (FOQA) program. However, implementing a FDM program not only requires an expensive investment in both aircraft flight data recorder (FDR) equipment and equipment on the ground, but also involves long-term labor costs to regularly collect and analyze flight data after flights are completed. Especially for GA, the implementation of a FDM program may be unaffordable considering the limited resources that GA operators have. Two examples of the many commercially available GA FDRs are Garmin's G1000 and Avidyne's Entegra. Automatic Dependent Surveillance Broadcast Out (ADS-B Out) is a precise satellite-based surveillance system which can continually broadcast flight data. The broadcasted flight data can be received by other nearby ADS-B In capable aircraft or ground-based ADS-B receivers. With the upcoming ADS-B mandated implementation date of January 1, 2020, there will be more GA aircraft equipped with ADS-B Out.

This paper explores the potential of ADS-B as an alternative data source for FDM for GA. After an introduction to FDM and ADS-B, then the structure and content of flight data broadcast by ADS-B Out are analyzed. Based on the basic flight parameters available in ADS-B messages, additional flight parameters are derived. By combining ADS-B data with aeronautical knowledge, additional flight metrics are developed from the standpoint of flight operation analysts. Finally, the potential of ADS$\mathrm{B}$ for supporting FDM is discussed.

\section{Flight Data Monitoring}

Among different types of aviation safety enhancement strategies, ICAO and other relevant agencies believe that flight data monitoring (FDM) is an effective method to proactively improve aviation safety by routinely collecting and analyzing aircraft operational data and detecting operational anomalies (International Civil Aviation Organization, 2010). Before the ICAO Annex 6 mandate that requires all airlines to implement a flight data monitoring program under regional legislation (International Civil Aviation Organization, 2010), the concept of FDM was presented by the Flight Safety Foundation named as the Flight Operational Quality Assurance (FOQA) in 1989 (Flight Safety Foundation, 1998). In 1990, the Federal Aviation Administration (FAA) officially initiated the development of FOQA program based on the basic concept presented by the Flight Safety Foundation earlier (Federal Aviation Administration, 2003). In 2004, the Advisory Circular 120-82 was initiated by the Voluntary Safety Program Branch AFS-230 of the FAA and was published detailing the procedures and standards to be followed for the development and implementation of a FOQA program for commercial operators (Federal Aviation Administration, 2004). In the U.S., FOQA is encouraged as a voluntary safety program by allowing commercial airlines and pilots to share deidentified aggregated information with the FAA so that the FAA can monitor national trends and issues in aircraft operations and allocate resources to address operational issues (Federal Aviation 
Administration, 2004). In addition to sharing de-identified flight data, routine flight data analysis is another key component of a FOQA program, and is more valuable and helpful from the standpoint of flight operators, because routine flight data analysis generates information to help improve flight safety proactively, shown as Figure 1.

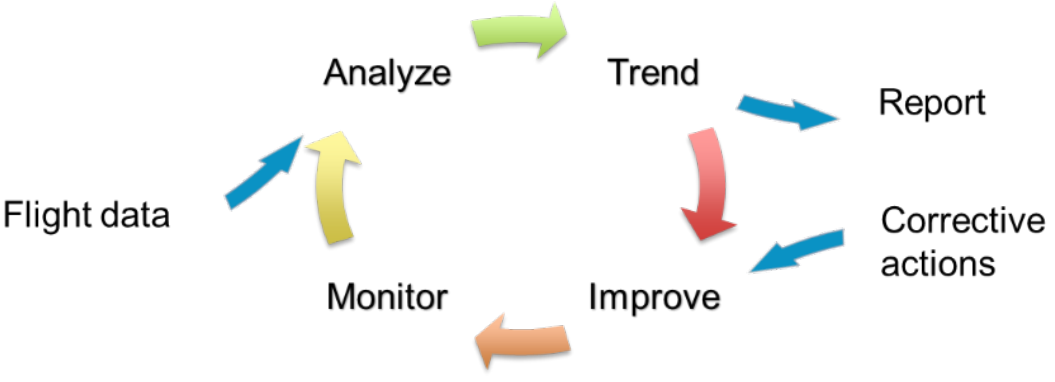

Figure 1. Procedure of routine flight data monitoring

Routine flight data analysis consists of three primary components: onboard flight operational parameters recording systems, Ground Data Replay and Analysis System (GDRAS), and air/ground data transfers (Federal Aviation Administration, 2004). The Quick Access Recorder (QAR) is one of the most popular onboard flight information recorders. Unlike standard Flight Data Recorders (FDR), also known as the "Black Box", which only record the last 25 hours of flight information ahead of an accident, and the data is only accessible in the event of an accident, a QAR for FOQA purpose records flight parameters every one second with the availability for collection and analysis upon the request of users (Wiley, 2007). Still, a well performed FOQA program requires commercial operators to designate specific personnel to collect flight data from the QAR, typically during scheduled maintenance (Federal Aviation Administration, 2004; Wiley 2007). The GDRAS is typically a software program used to transform, process, visualize, and analyze flight data. Upon the analysis results, flight data analysts could report usable information to safety managers to proactively respond the anomalies during flight operations. Another value of FOQA programs is the mutual sharing of de-identified flight data among other users and state agencies under a voluntary data sharing agreement to capture external flight information other than self-generated data.

However, the advantages of FDM/FOQA programs reply on stable and regular input of flight data. Given the current approaches to acquiring flight data from flight data recorders, which are expensive and require the cooperation of pilots and ground crew, to explore a relatively inexpensive approach to acquire flight data is believed to be necessary to popularize flight data analysis. 


\section{Automatic Dependent Surveillance}

Automatic Dependent Surveillance-Broadcast (ADS-B) is a precise satellite-based surveillance system, which retrieves aircraft's location, speed, altitude, and other data from the Global Positioning System (GPS) and broadcasts that information to ground stations and nearby aircraft, shown as Figure 2 (Federal Aviation Administration, 2016). ADS-B has two types of functions: ADS-B In and ADS-B Out. ADS-B Out periodically broadcasts encoded messages containing flight information; ADS-B In receives and decodes the messages broadcast by ADS-B Out. Theoretically, ADS-B In capable ground stations and aircraft are able to receive the aircraft information broadcast by all other ADS-B Out capable aircraft within the maximum range of the ADS-B Out signal, while communication satellites provide a solution to extend the coverage of the ADS-B Out signal.

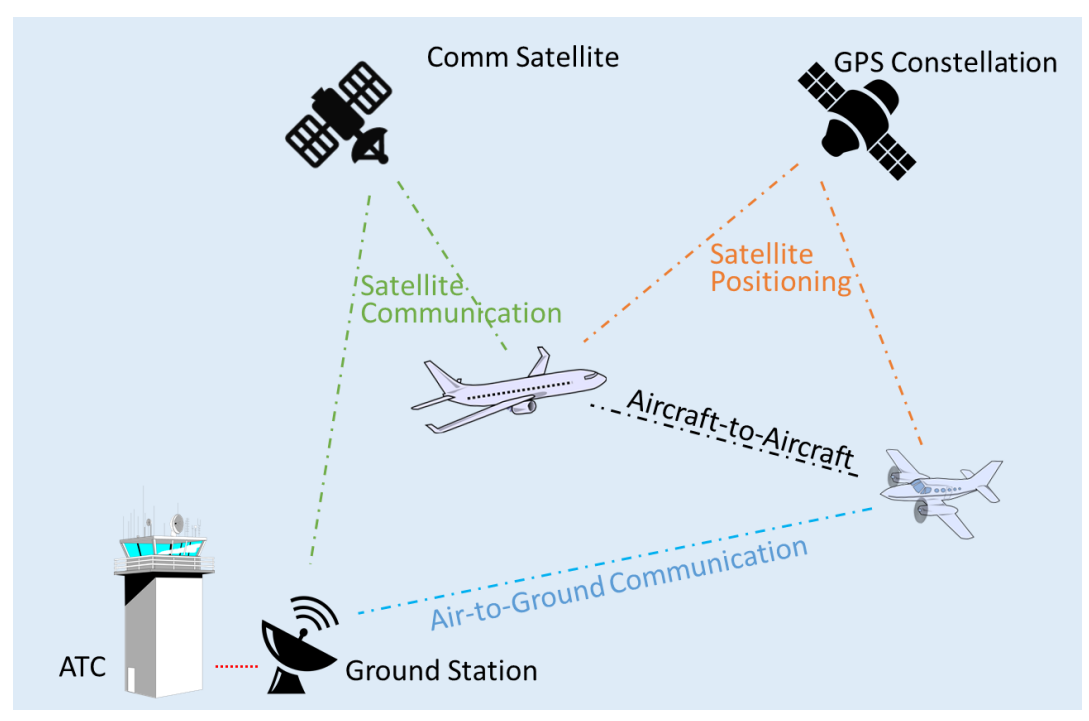

Figure 2. Overview of the ADS-B structure

To be effective January 1, 2020, the FAA requires all aircraft operating in designated airspace to be ADS-B Out equipped, which is believed to be an effective solution to improve air traffic safety and efficiency (14 Code of Federal Regulations, Part 91.225, 2011, Part 91.227, 2014). With the execution of the FAA's regulation on ADS-B Out, most aircraft operating in the U.S. will have to be ADS-B Out capable. Basically, there are two types of FAA compliant physical layers to support ADSB Out - Mode S Extended Squitter (Mode S ES) working on $1090 \mathrm{MHz}$, and the Universal Access Transceiver (UAT) working on $978 \mathrm{MHz}$; the selection of solutions depends on the aircraft operation altitude in the U.S. (Federal Aviation Administration, 2016). In general, Mode S ES has the advantage of being wideband and an international standard but operates on a congested frequency, and the UAT has high data bandwidth and fewer interferers but is not an international standard (Chen, Lo, Enge, \& Jan, 2014). In other words, the UAT can handle more data, so more aircraft in a concentrated area will work without overloading ground stations or other aircraft, but the Mode S transponders are already installed on most large commercial aircraft, which is believed to help minimize the expense of promoting ADS-B equipage (Federal Aviation Administration, 2014). To comply with the 2020 mandate, aircraft operating in Class A airspace - from 18000 feet mean sea level (MSL) altitude to and including 60000 feet MSL - must broadcast ADS-B Out position data using the Mode S ES; aircraft 
operating in designated airspace exclusively below 18000 feet MSL can use either Mode S ES or UAT (14 Code of Federal Regulations, Part 91.225, 2011). Currently, there are many aircraft already being equipped with a corresponding type of ADS-B Out system, but most of them are based on Mode S ES.

\section{Literature Review}

While commercial air transport services carry the most passengers and freight between major airports in the form of scheduled or non-scheduled flights, general aviation (GA) performs an important role in regional air transportation, recreation, agriculture, observation and patrol, flight training, and other tasks that supplement common aerial work.

With a goal of reducing the GA accident rates in the U.S. by 10 percent over the 10 years from 2009-2018 (Federal Aviation Administration, 2016), government and aviation industry have been working closely on a number of initiatives to improve GA safety, through organizations such as the General Aviation Joint Steering Committee (GAJSC), the National Transportation Safety Board (NTSB), the National Aeronautics and Space Administration (NASA), and the Partnership to Enhance General Aviation Safety, Accessibility and Sustainability (PEGASAS). Other international agencies, such as the European Aviation Safety Agency (EASA), the European General Aviation Safety Team (EGAST), and the General Aviation Safety Council (GASCo) are also working toward improved GA safety.

Similar to the approaches adopted by commercial aviation, aviation authorities and industry intend to develop and implement proactive data-driven, consensus-based approaches to identify and mitigate risks to GA operations. Launched in 1997, the GAJSC is a public - private partnership working to improve GA safety through data-driven risk reduction efforts based on education, training, and promoting new equipment in GA aircraft (General Aviation Joint Steering Committee, 2016). Loss of control accidents are identified as one of the most important challenges for GA safety since 40 percent of fixed wing GA fatal accidents are due to loss of control (National Transportation Safety Board, 2015). In an effort to address the challenge of loss of control, the GAJSC has concentrated on the study of loss of control with two specific work groups focusing on the phases of approach and landing, and other phases of flight respectively (General Aviation Joint Steering Committee, 2016). By 2016, the GAJSC has accomplished more than 29 safety enhancements, covering training, procedures, and technology, to mitigate the risks of loss of control (Federal Aviation Technology, 2016). The angle of attack (AoA) system, the aeronautical decision making (ADM), stabilized approach and landing, and airman certificate standards are examples of recent GAJSC accomplishments.

The Flight Data Monitoring (FDM) program is one of the most popular strategies to proactively improve flight safety by routinely collecting, analyzing and sharing de-identified flight data to provide more information, and deeper insight into flight operations environment (Federal Aviation Administration, 2004). However, the high cost of implementing a FDM program impedes GA to adopt this approach. Flight operational data collection and analysis is one of the primary factors determining the FDM programs to be expensive. Therefore, exploring an alternative data source for flight data monitoring is expected to be important to facilitate FDM programs in GA community. 


\section{Statement of Problem}

FDM is valuable, but the problem is that the implementation of a Flight Data Monitoring/Flight Operational Quality Assurance program requires a significant investment in onboard flight data recording systems, flight data processing and analysis tooling, and long-term labor cost for data collection. Based on the FAA published data by 2013, only 38 out of 88 air carriers operating under Part 121 have a FOQA program, of which 22 are large carriers by fleet size, 11 are medium carriers, and 5 are small carriers, shown as Figure 3 and Table 1 (Federal Aviation Administration, 2013). The relative lack of progress at medium and smaller air carriers is also due to a lack of funding to carry out focused strategies to assist small carriers (Federal Aviation Administration, 2013). In that case, exploring an inexpensive approach to undertake flight data monitoring appears crucial to popularize the deployment of FDM/FOQA programs in small air carriers and non-commercial operators. Decreasing the cost of flight data collection is one of the most effective breakthrough points to reduce the overall cost of routine flight data monitoring.

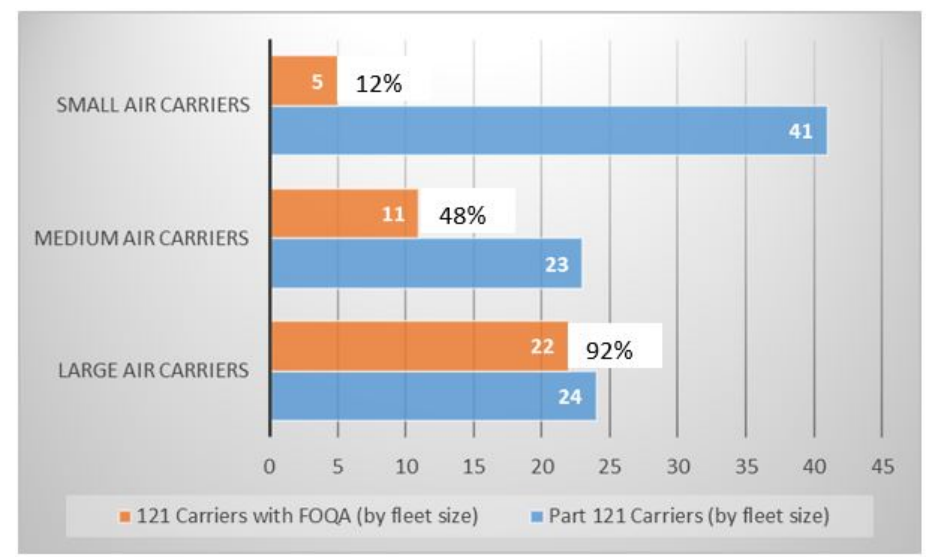

Figure 3. Deployment of FOQA programs in Part 121 carriers (Federal Aviation Administration, 2013).

Table 1

Carrier Classification by Fleet Size (Federal Aviation Administration, 2013).

\begin{tabular}{l|l|l|l} 
& Small Air Carriers & Medium Air Carriers & Large Air Carriers \\
\hline Size of Fleet & More than 50 aircraft & $16-50$ aircraft & 15 or fewer aircraft \\
\hline
\end{tabular}

\section{Methodology}

The Automatic Dependent Surveillance Broadcast Out (ADS-B Out) as one of the major components of the next generation air transportation system is required to be installed in all aircraft operating in most controlled airspace beginning from January 1, 2020 in the U.S. (14 Code of Federal Regulations, Part 91.225, 2011, Part 91.227, 2014). ADS-B-Out is a function on an aircraft or vehicle that periodically broadcasts its state vector (position and velocity) and other information derived from on-board systems in a format suitable for ADS-B In capable receivers (International Civil Aviation Organization, 2008). Theoretically, flight data can be received by properly using an ADS-B receiver, which is relatively inexpensive compared to a Quick Access Recorder (QAR) or other flight data 
recording systems. Features of ADS-B Out support it being an inexpensive solution to facilitate Flight Data Monitoring.

In order to examine the possibility of using ADS-B Out in flight data monitoring, the following research work was conducted in this study:

1. The structure and content of ADS-B Out messages were analyzed.

2. Based on the content of ADS-B messages, an initial set of flight metrics was developed from the standpoint of flight data analysts.

3. Additional flight metrics were developed by incorporating other aeronautical information.

4. The potential of ADS-B data was discussed in terms of facilitating Flight Data Monitoring.

\section{Results}

\section{ADS-B Message Structure and Content}

ADS-B uses the global positioning system (GPS) to determine aircraft's location and airspeed, derives other flight data from onboard avionics, and broadcasts all information periodically over the $1090 \mathrm{MHz}$ extended squitter (International Civil Aviation Organization, 2008). The extended squitter is an extended portion of the mode $S$ transponders transmission bandwidth, which contains the ADS$\mathrm{B}$ information in the form of data packets. According to ICAO's Technical Provisions of Mode $S$ Services and Extended Squitter (International Civil Aviation Organization, 2008), ADS-B Out data is structured with a standard format. An ADS-B message is 112 bits long encoded either in BIN format or HEX format. The structure of ADS-B Out data in this research can be formatted as Table 2.

Table 2

Structure of an $A D S-B$ message

\begin{tabular}{l|l|l} 
Bit from & Bit to & Type of Data \\
\hline 1 & 5 & Downlink Format \\
\hline 6 & 8 & Message Subtype \\
\hline 9 & 32 & ICAO Aircraft Address \\
\hline 33 & 88 & Data Frame \\
\hline 89 & 112 & Parity Check \\
\hline
\end{tabular}

The content of an ADS-B message is encoded in different sections in the 112 bits of the message. Each type of data functions to convey the necessary information to transmit relevant aircraft data. For example, the Downlink Format (DF), from bit 1 to bit 5, is used to identify the type of message, the DF for ADS-B message is fixed as 17, or 10001 in binary format. The most aircraft information is contained in the Data Frame, from bit 33 to bit 88. In the Data Frame, the value of bit 33 to 37 encodes the Type of Code, which is used to indicate the specific aircraft information, shown as Table 3 . 
Table 3

$A D S-B$ message types

\begin{tabular}{l|l} 
Type Code (TC) & Content \\
\hline 1 to 4 & Aircraft identity \\
\hline 5 to 8 & Surface position \\
\hline 9 to 18 & Airborne position (Barometric altitude) \\
\hline 19 & Airborne velocities \\
\hline 20 to 22 & Airborne position (GNSS height) \\
\hline 23 & Test message \\
\hline 24 & Surface system status \\
\hline 25 to 27 & Reserved \\
\hline 28 & Extended squitter AC status \\
\hline 29 & Target state and status (V.2) \\
\hline 30 & Reserved \\
\hline 31 & Aircraft operation status \\
\hline
\end{tabular}

Based on the ADS-B message types shown as above, a series of optional aircraft parameters can be encoded into ADS-B messages. In general, aircraft information that can be transmitted through ADSB messages includes airborne position, airborne velocity, surface position, aircraft identification and emitter category, and event-driven protocols (ICAO, 2013). A comprehensive list of aircraft parameters that could be transmitted through ADS-B messages can be found in the ICAO Doc 9871 - Technical Provisions for Mode S Services and Extended Squitter (ICAO, 2008). In this paper, a set of flight parameters that most likely could be decoded from ADS-B messages is summarized as Table 4.

The prominent flight parameters that could be decoded from ADS-B messages include Aircraft Callsign, Latitude and Longitude of Aircraft Position, Barometric Altitude above the Mean Sea Level (MSL) or the Height of Aircraft above the Ellipsoid (HAE), Ground Speed, Ground Track, Airspeed, Heading, Vertical Speed, and other indicators of data integrity, accuracy, or uncertainties of the position measurement from GPS unit.

\section{Flight Metrics Developed from ADS-B Data}

With the purpose of supporting Flight Data Monitoring and flight operations analysis, a set of potential flight metrics related to exceedances, safety events, pilot performance, and fleet performance are developed using the flight data transmitted by ADS-B Out, shown as Table 4.

Given the limited number of basic flight data that is broadcast by ADS-B Out, the identified flight metrics can be directly retrieved from ADS-B messages or be derived with additional aeronautical and physics knowledge. For instance, the Glide Angle could be derived using Ground Speed, Vertical Speed, and Timestamp as shown in Figure 4. 


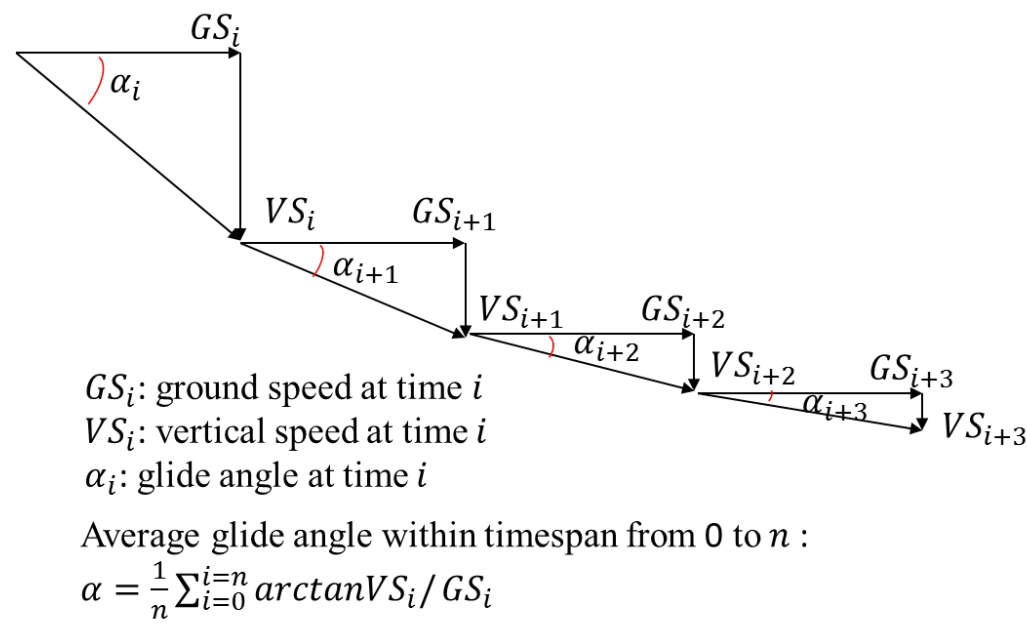

Figure 4. Derivation of the glide angle using basic ADS-B data

Table 4

Prominent flight information contained in $A D S-B$ messages

\begin{tabular}{l|l|l} 
Data Type & Primary & Alternative \\
\hline \multirow{2}{*}{ Time } & Timestamp of received frame & Timestamp of received frame \\
\hline Aircraft Identification & ICAO ID/Callsign & ICAO ID/Callsign \\
\hline \multirow{2}{*}{ Surface Position } & Latitude & Latitude \\
\cline { 2 - 3 } & Longitude & Longitude \\
\hline \multirow{2}{*}{ Airborne Position } & Altitude (Barometric Altitude) & Altitude (GNSS Height) \\
\cline { 2 - 3 } & Ground Track & Heading \\
\hline \multirow{2}{*}{ Velocities } & Ground Speed & Airspeed \\
\cline { 2 - 3 } & Vertical Speed & Vertical Speed \\
\hline
\end{tabular}

Note: The primary flight information is transmitted as default by ADS-B Out; alternative parameters are transmitted as optional or when the primary information is not available.

Tables 4 and 5 show the initial and basic metrics; and all of these metrics can be retrieved or derived by directly using corresponding ADS-B data. More metrics are expected to be developed based on the purposes of specific flight data analyses. The list of flight metrics is expected to be extendable to meet particular requests of flight analysts. Flight Data Monitoring is used to detect flight operational exceedances, monitor pilot and fleet performance, and identify safety related occurrences. To demonstrate some of the flight metrics derivable from ADS-B messages, an additional set of flight metrics is developed by incorporating other common aeronautical information, shown as Table 6 . 
Table 5

Flight Metrics identified using basic $A D S-B$ data

\begin{tabular}{|c|c|c|c|}
\hline Flight Metric & ADS-B Data Needed & Flight Metric & ADS-B Data Needed \\
\hline Flight altitude & Altitude & Maximum altitude & Altitude \\
\hline Ground speed & Ground speed & Airspeed & Airspeed \\
\hline \multirow{2}{*}{ Vertical speed } & \multirow{2}{*}{ Vertical speed } & \multirow{2}{*}{ Vertical g-force } & Vertical speed \\
\hline & & & Timestamp \\
\hline \multirow{3}{*}{ Glide angle } & Ground speed & \multirow{3}{*}{ Climb angle } & Ground speed \\
\hline & Vertical speed & & Vertical speed \\
\hline & Timestamp & & Timestamp \\
\hline \multirow{2}{*}{ Heading } & \multirow{2}{*}{ Heading } & \multirow{2}{*}{ Heading change rate } & Heading \\
\hline & & & Timestamp \\
\hline \multirow{2}{*}{ Flight time } & Aircraft ID & \multirow{2}{*}{$\begin{array}{l}\text { Longitudinal } \\
\text { acceleration }\end{array}$} & Airspeed \\
\hline & Timestamp & & Timestamp \\
\hline \multirow{4}{*}{ GPS track } & Latitude & \multirow{4}{*}{ Night time operations } & Aircraft ID \\
\hline & Longitude & & Timestamp \\
\hline & Altitude & & \\
\hline & Timestamp & & GPS track \\
\hline \multirow{3}{*}{ Daytime operations } & Aircraft ID & & \\
\hline & Timestamp & & \\
\hline & GPS track & & \\
\hline
\end{tabular}

\section{Discussion of ADS-B Data for Flight Data Monitoring}

The purpose of this study is to explore the potential of ADS-B data to support Flight Data Monitoring (FDM). Because the motivation is to reduce the high cost of Flight Data Monitoring, compared to other flight data collection methods, ADS-B provides a low-cost approach to collect certain types of flight data without the cooperation of pilots or ground crew, as described in Automatic Dependent Surveillance. Given that advantage of ADS-B, the potential of ADS-B data is examined by qualitatively analyzing the list of flight metrics from the different perspectives of Flight Data Monitoring. 
Table 6

Flight metrics identified with additional aeronautical information

\begin{tabular}{|c|c|c|c|c|c|}
\hline $\begin{array}{l}\text { Additional } \\
\text { Metric }\end{array}$ & Basic Metrics & $\begin{array}{l}\text { Aeronautical } \\
\text { Information }\end{array}$ & Additional Metric & $\begin{array}{l}\text { Basic } \\
\text { Metrics }\end{array}$ & $\begin{array}{l}\text { Aeronautical } \\
\text { Information }\end{array}$ \\
\hline $\begin{array}{l}\text { Excessive } \\
\text { longitudinal } \\
\text { acceleration } \\
\end{array}$ & $\begin{array}{l}\text { Longitudinal } \\
\text { acceleration }\end{array}$ & $\begin{array}{l}\text { Exceedance } \\
\text { information }\end{array}$ & $\begin{array}{l}\text { Excessive vertical } \\
\text { acceleration }\end{array}$ & $\begin{array}{l}\text { Vertical } g- \\
\text { force }\end{array}$ & $\begin{array}{l}\text { Exceedance } \\
\text { information }\end{array}$ \\
\hline $\begin{array}{ll}\text { Loss } & \text { of } \\
\text { separation } & \\
\end{array}$ & GPS track & $\begin{array}{l}\text { Separation } \\
\text { standards }\end{array}$ & $\begin{array}{ll}\text { Altitude above } \\
\text { ground level }\end{array}$ & Altitude & $\begin{array}{ll}\text { Ground level } \\
\text { above MSL }\end{array}$ \\
\hline $\begin{array}{l}\text { Deviation from } \\
\text { runway } \\
\text { centerline }\end{array}$ & GPS track & $\begin{array}{l}\text { Airport } \\
\text { information }\end{array}$ & $\begin{array}{l}\text { Altitude en-route } \\
\text { minimum }\end{array}$ & Altitude & Flight plan \\
\hline $\begin{array}{l}\text { Undershoot/O } \\
\text { vershoot }\end{array}$ & GPS track & $\begin{array}{l}\text { Airport } \\
\text { information }\end{array}$ & Runway excursion & GPS track & $\begin{array}{l}\text { Airport } \\
\text { information }\end{array}$ \\
\hline $\begin{array}{l}\text { Runway } \\
\text { incursion }\end{array}$ & GPS track & $\begin{array}{l}\text { Airport } \\
\text { information }\end{array}$ & $\begin{array}{l}\text { Estimated distance } \\
\text { from reported } \\
\text { weather hazards }\end{array}$ & GPS track & $\begin{array}{l}\text { Weather } \\
\text { information }\end{array}$ \\
\hline $\begin{array}{l}\text { Runway float } \\
\text { time }\end{array}$ & GPS track & $\begin{array}{l}\text { Airport } \\
\text { information }\end{array}$ & $\begin{array}{l}\text { Altitude in relation } \\
\text { to low-altitude en- } \\
\text { route chart } \\
\text { minimum } \\
\text { obstruction } \\
\text { clearance altitude }\end{array}$ & Altitude & $\begin{array}{l}\text { Low-altitude } \\
\text { chart } \\
\text { information }\end{array}$ \\
\hline $\begin{array}{l}\text { Altitude in } \\
\text { relation to } \\
\text { sectional chart } \\
\text { maximum } \\
\text { elevation }\end{array}$ & Altitude & $\begin{array}{l}\text { Sectional chart } \\
\text { information }\end{array}$ & $\begin{array}{l}\text { Altitude in relation } \\
\text { to low-altitude en- } \\
\text { route chart } \\
\text { minimum en-route } \\
\text { altitude }\end{array}$ & Altitude & $\begin{array}{l}\text { Low-altitude } \\
\text { chart } \\
\text { information }\end{array}$ \\
\hline
\end{tabular}

Exceedance detection. Exceedance detection is one of the most prominent approaches in flight operational data analysis (Federal Aviation Administration, 2004). Exceedance detection looks for deviation from flight manual limits and standard operational procedures (SOPs) (Australian Civil Aviation Safety Authority, 2011). In other words, the exceedance detection approach monitors interesting aircraft parameters and triggers a warning or draws the attention of safety specialists when parameters reach the preset limits or baselines under certain conditions. Usually, the focus list of aircraft parameters coincides with the flight operations manual or operator's SOPs. The pitch at takeoff, the approach speed, the glide path angle, and the climb speed are examples of typical flight parameters in the watch list (Federal Aviation Administration, 2004). Typically, exceedance levels are developed through an assessment of aircraft operations manuals, training programs, and risk assessment processes as part of the overall safety program (Federal Aviation Administration, 2004).

Therefore, the interesting exceedances are quite diverse and depend on specific analytical purposes. Roughly, exceedance detection can identify over 60 basic types of events, and more events and could be developed upon the carrier's operations manual (Federal Aviation Administration, 2004). Based on the flight parameters and flight metrics developed out of ADS-B messages, exceedances determined by Airspeed, Flight Altitude, Vertical Speed, Aircraft Location, or the combination of these parameters are most likely to be detected using ADS-B messages. However, Bank Angle, Pitch, and Yaw are not contained in typical ADS-B messages currently. These three parameters are typically used to describe the aircraft attitude and are expected to be important for flight data analysis, because many critical flight conditions and exceedances are detected by analyzing aircraft attitude. Threshold 
for stall speed and aircraft structural load factor are examples of interesting metrics for flight safety analysts. Therefore, exceedances related to Bank Angle, Pitch, or Yaw are unlikely to be detected using only the current version of ADS-B messages.

Safety events. Safety events refer to aviation occurrences that are accidents and incidents. Safety events are defined by the Commercial Aviation Safety Team of ICAO to permit analysis of flight data in support of safety initiatives (The Commercial Aviation Safety Team and ICAO Common Taxonomy, 2013). Currently, there are 36 categories of occurrences defined by ICAO, see ICAO Aviation Occurrence Categories version 4.6 (The Commercial Aviation Safety Team and ICAO Common Taxonomy, 2013). Based on the set of flight metrics explored in this study, 11 categories of occurrences are identified to be supported by ADS-B messages are expected to support to identify 11 categories of occurrences, described in Table 7.

Table 7

Identified a potential role for ADS-B data for 11 of 36 ICAO defined safety occurrences

\begin{tabular}{l|l|l|l} 
ICAO Defined Occurrence & Description & ADS-B \\
(Mode S ES)
\end{tabular}


Table 7 (cont.)

Identified a potential role for $A D S-B$ data for 11 of 36 ICAO defined safety occurrences

\begin{tabular}{|c|c|c|c|}
\hline ICAO Defined Occurrence & Description & Data needed & $\begin{array}{l}\text { ADS-B } \\
\text { (Mode S ES) }\end{array}$ \\
\hline \multirow{3}{*}{ Ground collision } & \multirow{3}{*}{$\begin{array}{l}\text { Identify collision while taxiing } \\
\text { to or from a runway in use }\end{array}$} & Latitude/Longitude & $\sqrt{ }$ \\
\hline & & Altitude & $\sqrt{ }$ \\
\hline & & $\begin{array}{ll}\text { Airport } & \text { surface } \\
\text { information } & \end{array}$ & \\
\hline \multirow{5}{*}{ Loss of Control-Ground } & \multirow{5}{*}{$\begin{array}{l}\text { Identify loss of aircraft control } \\
\text { while the aircraft is on the } \\
\text { ground }\end{array}$} & Latitude/Longitude & $\sqrt{ }$ \\
\hline & & Altitude & $\sqrt{ }$ \\
\hline & & Terrain information & \\
\hline & & Ground speed & $\sqrt{ }$ \\
\hline & & $\begin{array}{ll}\begin{array}{l}\text { Airport } \\
\text { information }\end{array} & \text { surface } \\
\end{array}$ & \\
\hline \multirow{8}{*}{ Loss of Control-Inflight } & \multirow{8}{*}{$\begin{array}{l}\text { Identify loss of aircraft control } \\
\text { while, or deviation from } \\
\text { intended flightpath, in flight }\end{array}$} & Latitude/Longitude & $\sqrt{ }$ \\
\hline & & Altitude & $\sqrt{ }$ \\
\hline & & Airspeed & $\sqrt{ }$ \\
\hline & & Roll angle & \\
\hline & & Pitch angle & \\
\hline & & Yaw angle & \\
\hline & & Ground speed & $\sqrt{ }$ \\
\hline & & Angle of attack & \\
\hline \multirow{4}{*}{$\begin{array}{l}\text { Runway } \\
\text { incursion/excursion }\end{array}$} & \multirow{4}{*}{$\begin{array}{l}\text { Identify occurrences at an } \\
\text { aerodrome involving the } \\
\text { incorrect presence of an } \\
\text { aircraft, vehicle, or person on } \\
\text { the protected area of a surface } \\
\text { designated for the landing and } \\
\text { takeoff aircraft }\end{array}$} & Latitude/Longitude & $\sqrt{ }$ \\
\hline & & Altitude & $\sqrt{ }$ \\
\hline & & Ground speed & $\sqrt{ }$ \\
\hline & & $\begin{array}{ll}\text { Airport } & \text { surface } \\
\text { information } & \end{array}$ & \\
\hline \multirow{4}{*}{ Turbulence encounter } & \multirow{4}{*}{$\begin{array}{l}\text { Identify and locate in-flight } \\
\text { turbulence encounter }\end{array}$} & Latitude/Longitude & $\sqrt{ }$ \\
\hline & & Altitude & $\sqrt{ }$ \\
\hline & & $\begin{array}{l}\text { Meteorological } \\
\text { information }\end{array}$ & \\
\hline & & Pilot report & \\
\hline \multirow{3}{*}{ Undershoot/Overshoot } & \multirow{3}{*}{$\begin{array}{l}\text { Identify touchdown off the } \\
\text { runway }\end{array}$} & Latitude/Longitude & $\sqrt{ }$ \\
\hline & & Altitude & $\sqrt{ }$ \\
\hline & & $\begin{array}{ll}\begin{array}{l}\text { Airport } \\
\text { information }\end{array} & \text { surface } \\
\end{array}$ & \\
\hline \multirow{5}{*}{ Unintended flight in IMC } & \multirow{5}{*}{$\begin{array}{l}\text { Identify unintended flight in } \\
\text { Instrument Meteorological } \\
\text { Conditions }\end{array}$} & Latitude/Longitude & $\sqrt{ }$ \\
\hline & & Altitude & $\sqrt{ }$ \\
\hline & & $\begin{array}{l}\text { Meteorological } \\
\text { information }\end{array}$ & \\
\hline & & Vertical rate & $\sqrt{ }$ \\
\hline & & Pilot report & \\
\hline
\end{tabular}


Pilot and fleet performance. Pilot and fleet performance is another aspect that operators are usually interested in monitoring. Basic descriptive statistical analysis can assist in identifying trends, outliers, and signal changes in performance when employed properly, and is usually used to monitor pilot and fleet performance (Global Aviation Safety Network, 2003). Unlike exceedance and safety occurrence detection, statistical approaches to monitor the pilot and fleet performance can provide operators an overall view of performance. The findings of pilot and fleet performance monitoring, such as the distributions and trends of interesting indicators, can be important for developing and corrective actions to improve safety and operation efficiency. As per the initial analysis of ADS-B messages in this study, flight metrics could potentially be used to evaluate individual pilots. Many of those metrics could bring up information valuable to pilots in terms of personal performance during flight, such as flight time, night/day time operations, and deviation from runway centerline. In addition, airport and fleet operators can also take the advantages of ADS-B by adopting interesting metrics to monitor fleet operational performance. The number of operations at a specific airport or in a particular region is one of the example metrics that might interest operators. The number of aircraft parameters contained in ADS-B messages are limited compared to the number of parameters in Flight Data Recorders. ADS-B could still be treated as a low-cost approach to collect flight operational data for analyses.

\section{Conclusion}

This study investigated ADS-B as an alternative data source for GA flight data analysis as opposed to the high cost of traditional Flight Data Monitoring programs that require on-board flight data recording equipment and post-flight analyses. Since ADS-B Out messages are broadcasted, the data may be collected using equipment on the ground. The analysis of current version ADS-B messages revealed 11 types of primary flight parameters that can be decoded from ADS-B messages. In addition, a list of 15 initial flight metrics was developed using flight parameters transmitted by ADSB Out. A list of 14 additional metrics was developed by incorporating common aeronautical information or other relevant information. Qualitative analysis of the developed flight metrics demonstrates a wide range of functions when ADS-B could be used in Flight Data Monitoring in terms of post-flight data analysis for exceedance detection, safety occurrence identification, and pilot and fleet performance monitoring.

Traditional Flight Data Monitoring programs can identify over 60 basic types of events related to flight safety, because current Flight Data Recorders can record over 1,000 aircraft parameters and are used as the data source for FDM programs (Federal Aviation Administration, 2004; Campbell, 2007). However, due to the limited number of flight parameters in ADS-B messages, ADS-B shows certain disadvantages to fully support some typical functions of flight data analysis; for example, to identify the attitude of aircraft through Roll, Pitch, and Yaw. In addition to the primary function of ADS-B as a traffic surveillance system, this study proposes to extend the use of ADS-B to the area of flight data monitoring for general aviation, and serve as a reference for relevant future study. Based on the findings of this paper, further study would focus on developing more useful flight metrics upon specific request of GA operators. In the meantime, the ADS-B technology is still under development, a corresponding study could be investigated to extend the capability of ADS-B in supporting Flight Data Monitoring. 


\section{Acknowledgement}

This research was partially funded by the Federal Aviation Administration (FAA) under the Center of Excellence for General Aviation Research PEGASAS Cooperative Agreement No. 12-CGA-PU AM8, AM25, AM35. The FAA technical monitor was Michael Vu of the FAA Aviation Research Division. The views expressed in this paper are those of the authors and do not necessarily reflect those of the FAA. The information in this research does not constitute FAA Flight Standards or FAA Aircraft Certification policy. 


\section{References}

Australian Civil Aviation Safety Authority. (2011). Guidance on the establishment of a flight data analysis program - safety management systems (CAAP SMS-4(0)). Australian: Civil Aviation Advisory Publication.

Automatic dependent surveillance-broadcast (ADS-B) out equipment and use, 14 C.F.R. $\int 91.225$ (2011).

Automatic dependent surveillance-broadcast (ADS-B) out equipment performance requirements, 14 C.F.R. $\int 91.227$ (2014).

Campbell, N. A. H. (2007). The evolution of flight data analysis. 2007 ANZSASI conference regional seminar. Wellington, New Zealand. Retrieved from http://asasi.org/papers/2007/The_Evolution_of_Flight_Data_Analysis_Neil_Campbell.pd f.

Chen, Y. H., Lo, S., Enge, P., \& Jan, S. S. (2014). Evaluation \& comparison of ranging using Universal Access Transceiver (UAT) and $1090 \mathrm{MHz}$ Mode S Extend Squitter (Mode S ES). Proceedings from 2014 IEEE/ION Position, Location and Navigation Symposium - PLANS 2014, Monterey, CA, 2014, pp. 915-925. doi: 10.1109/PLANS.2014.6851456.

Federal Aviation Administration. (n.d.). Destination 2025. Washington, DC: Retrieved from https://www.faa.gov/about/plans_reports/media/Destination2025.pdf

Federal Aviation Administration. (2003). Flight operational quality assurance aviation rulemaking committee. (DOT Order No. 1110.131A). Washington, DC: U.S. Government Printing Office.

Federal Aviation Administration. (2004). Flight operational quality assurance (AC No. 120-82). Retrieved from

http://www.airweb.faa.gov/Regulatory_and_Guidance_Library/rgAdvisoryCircular.nsf/0/4 0c02fc39c1577b686256e8a005afb0a/\$FILE/AC120-82.pdf

Federal Aviation Administration. (2013). Audit report: FAA and industry are advancing the airline safety act, but challenges remain to achieve its full measure (AV-2013-037). Retrieved from https://www.oig.dot.gov/sites/default/files/Safety $\% 20$ Act $\% 202010 \% 20$ Report $\% 5 E 1-31$ 13.pdf

Federal Aviation Administration. (2014). Aviation safety information analysis and sharing project demonstration for general aviation. Federal Register, 79 (60), 17638-17639.

Federal Aviation Administration. (2016). The NextGen programs. Retrieved from https://www.faa.gov/nextgen/programs/

Federal Aviation Administration. (2016). Fact sheet - General aviation safety. Retrieved from http://www.faa.gov/news/fact_sheets/news_story.cfm?newsId=20574

Flight Safety Foundation. (1998). Aviation safety: U.S. efforts to implement flight operational quality assurance programs. Flight Safety Digest, 17(7-9), 1-54. 
General Aviation Joint Steering Committee. (2016). About us. Retrieved from http://www.gajsc.org/about-us/

General Aviation Joint Steering Committee. (2016). GA safety performance. (AVS Safety Performance GAJSC Pareto). http://www.gajsc.org/2016/01/ga-safety-performance-fy16/

Global Aviation Safety Network Working Group B. (2003). Guide to methods \& tools for airline flight safety analysis. Retrieved from https://flightsafety.org/files/analytical_methods_and_tools.pdf.

International Civil Aviation Organization. (2008). Technical provisions for mode S services and extended squitter (Doc 9871). Montreal, Canada: Author.

International Civil Aviation Organization. (2013). Guide on technical and operational considerations for the implementation of ADS-B in the SAM region (Version 1.2). Lima, Peru: Author.

The Commercial Aviation Safety Team/ICAO Common Taxonomy. (2013). Aviation occurrence categories: Definitions and usage notes (Version 4.6). Retrieved from http://www.intlaviationstandards.org/Documents/OccurrenceCategoryDefinitions.pdf

U.S. National Transportation Safety Board. (2015). NTSB 2015 most wanted transportation safety improvements: Prevent loss of control in flight in general aviation. Washington, DC: Author.

U.S. National Transportation Safety Board. (2016). NTSB 2014 US civil aviation accident statistics. Washington, DC: Author. Retrieved from https://ntsb.gov/investigations/data/Pages/AviationDataStats2014.aspx.

Wiley, J. (2007, June). C-FOQA: Has its time arrived? Business \& Commercial Aviation, 100(6), 76-82. 